\title{
AN INTEGRATED FRAMEWORK FOR SHIP STRUCTURAL OPTIMISATION IN THE CONTRACT DESIGN PHASE
}

\author{
Abbas Bayatfar \\ SE-ANAST Research Unit, ArGEnCo Department, \\ Applied Science Faculty, University of Liege, \\ Liege, Belgium \\ a.bayatfar@uliege.be

\section{Renaud Warnotte} \\ SE-ANAST Research Unit, ArGEnCo Department, \\ Applied Science Faculty, University of Liege, \\ Liege, Belgium \\ renaud.warnotte@uliege.be
}

\author{
Jose Mishael \\ SE-ANAST Research Unit, ArGEnCo Department, \\ Applied Science Faculty, University of Liege, \\ Liege, Belgium \\ jmjoseph@uliege.be
}

\section{Philippe Rigo}

SE-ANAST Research Unit, ArGEnCo Department, Applied Science Faculty, University of Liege, Liege, Belgium ph.rigo@uliege.be

\begin{abstract}
This paper demonstrates the implementation of an integrated workflow for the finite element-based structural assessment/optimization of a 3D midship segment of RoPax vessel within the contract design phase. Commercial software such as AVEVA Marine ${ }^{\circledR}$, ANSYS $^{\circledR}$ and modeFRONTIER ${ }^{\circledR}$ and newly developed in-house tools/modules have been integrated under an automated iterative routine. The structural optimisation carried out with an aim to reduce the structural weight of the ship with least value for vertical centre of gravity. Constraints implemented in the optimization include relevant $B V$ rules and shipyard requirements.The work is performed within the framework of European Union's HOLISHIP (2016-2020) project.
\end{abstract}

Keywords: Holistic Structural Optimisation, FEA, RoPax vessel.

\section{INTRODUCTION}

Shipbuilding and the shipping sector face increasing pressure to balance the conflicting needs and requirements of improving safety, reducing environmental impact, increasing flexibility for varying operational conditions, improving life cycle cost/performance, etc. within the context of a highly competitive market.

Meeting such significant challenges requires the use of a holistic, multi-disciplinary and multi-objective design optimization platform from the earliest design stages in the traditional ship design process. The creation of such a platform was, to some extent, ad- dressed during some former research-based EU-funded projects such as IMPROVE [1] (for examples see [2-3]), and BESST [4] (see [5] for more).

In continuation of preceding work undertaken, the EU launched a new R\&D project in 2016, first initiated by Papanikolaou in 2010 [6]. A very large team of European partners set out to comprehensively develop the concept of a holistic approach to the optimization of ship design and has been collaborating to implement the approach within the context of the EU Horizon $2020 \mathrm{R} \& \mathrm{D}$ project dubbed HOLISHIP, or the 'Holistic Optimization of Ship Design and Operation for Life Cycle' [7]. 
The HOLISHIP project addresses the different design steps from the concept and contract design of vessels to virtual prototyping for design, and operational assessment. It aims at considering all relevant design aspects, namely energy efficiency, safety, environmental compatibility, production and lifecycle cost using holistic optimization platforms that aim at delivering the right vessel(s) for future transport tasks. To this end, a modern, flexible computer-aided engineering (CAE) environment, based on CAESES $^{\oplus}$ (www.caeses.com) as the process integration and design optimization (PIDO) environment, is being used to integrate all the important disciplines of conceptual and contractual design under the greater umbrella of advanced parametric modelling tools to enable the parametric, multi-objective and multidisciplinary optimization of ship products. (A detailed description of the project can be found in [8], while a quick overview can be gained from [9-10]).

Recent feedback from shipyards indicates that efficient and effective weight reduction is one of the main technical requirements of the design process (Rigo et al. [11]). To meet this need, within the EU HOLISHIP project, an integrated workflow for FE-based structural assessment/optimization process (see Section 2, Fig. 1) has been developed to systematically serve relevant application cases in the contract design stage where advanced assessment methods/tools are necessary.

The main objective of this paper is to demonstrate an integrated workflow for FEbased structural design assessment/optimization of a typical 3D midship segment of RoPax vessel. To this end, a number of existing tools along with their new script/batch-mode developments (namely AVEVA Marine ${ }^{\circledR}$, ANSYS $^{\circledR}$ and modeFRONTIER $^{\circledR}$ ) as well as some new in-house tools/modules (e.g. Scantling-Spacing Updater, FE Result Extractor, etc.) have been integrated under an automated iterative routine (see Section 3).

\section{GENERAL METHODOLOGY}

In the contract design phase, a FE-based methodology is considered to perform the structural design assessment/optimisation of the relevant application cases (e.g. RoPax vessel) improving the structural behaviour/weight. Fig. 1 presents the integrated FE-based structural design assessment/optimisation workflow for contract stage. AVEVA Marine ${ }^{\circledR}$ receives the dimensions and scantlings from CAESES ${ }^{\circledR}$ and creates parametric 3D CAD model, which is used to generate the 3D FE model. The process is semi-automatic.

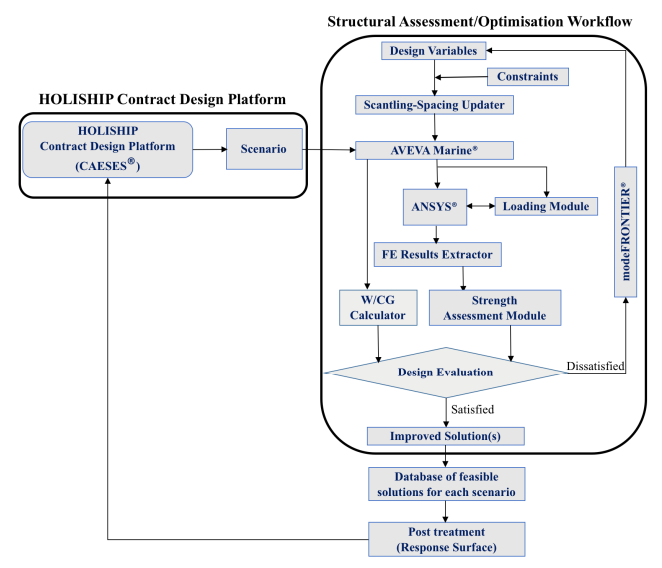

Fig.1. The integrated FE-based structural optimisation workflow for the contract design stage

On the basis of the data received from CAESES $^{\circledR}$ (contract design platform), a 3D parametric structural model was built in AVEVA Marine ${ }^{\circledR}$ considering plate thickness, stiffener scanting/spacing, etc. as design variables. The $3 \mathrm{D}$ parametric structural model is considered as a reference design model for structural assessment/optimisation process. The magnitudes of design variables are proposed by optimiser, modeFRONTIER $^{\circledR}$ while they are subject to technology and equality constraints from the yard/designer. A new in-house development 
called 'Scantling-Spacing Updater' (see Section 3) modifies AVEVA Marine ${ }^{\circledR}$ readable text files with optimiser proposed values. The updated readable text files are read into AVEVA Marine ${ }^{\circledR}$ to produce an idealised 3D geometry with respect to FE-based structural assessment needs.

The idealised 3D geometry is transferred to $\mathrm{ANSYS}^{\circledR}$ for carrying out the required finite element analysis (FEA). The appropriate loads and boundary conditions (BCs) are provided and applied on FE structural design model through a new in-house development named 'Loading Module' (see Section 3). The loads/BCs are considered on the basis of $\mathrm{BV}$ rules. As the loaded FE structural design model is solved using ANSYS ${ }^{\circledR}$, the new inhouse tool 'FE Result Extractor' (see Section 3) extracts and feeds the FE results (e.g. longitudinal stress, shear stress, etc.) into the 'Strength Assessment Module' (see Section 3 ), which is also a newly developed tool for strength checks complying with the BV strength criteria.

The modeFRONTIER ${ }^{\circledR}$ software, together with some new script/batch-mode developments, steers the above-described process under an automated routine. In the automated optimisation cycle, the structural weight/CG, assessed by AVEVA Marine ${ }^{\circledR}$, is considered so that the design objective functions will be minimised in the optimisation loop with modeFRONTIER ${ }^{\circledR}$. The optimisation is carried out with two objectives: total ship steel weight and vertical centre of gravity. The optimisation process is searching for the best design with least steel weight and minimum elevation of the centre of gravity.

The values of the design objective functions and the structural constraints such as yielding and buckling checks are used by modeFRONTIER ${ }^{\circledR}$ at each iteration to generate new sets of design variable values. This iterative process continues and a set of improved solutions are selected, depending on the expected level of accuracy (linked to the convergence of the optimisation process) and the available time.
The structural assessment/optimisation is launched in order to obtain a set of improved solutions (structural design/scantling) for different configurations provided by the contract design platform. The above procedure is repeated for each new hull form/GA design configuration. In this way, the output database is enriched in order to later derive surrogate models (Response Surface Models (RSM)) of the steel weight and the vertical position of the centre of gravity (CG), which can be used for relevant application cases.

\section{TOOL DESCRIPTION}

The present work used existing commercial software and newly developed tools for structural optimization. Few of the tools are explained hereinafter.

\subsection{Existing Tools}

- AVEVA Marine ${ }^{\circledR}$

AVEVA Marine ${ }^{\circledR}$ is a ship design and production system with origins in Steerbear, developed by KCS, part of the Kockums Shipyard in the 1960s. The core aim of the software is to prepare a $3 \mathrm{D}$ model of the ship's structure and internal system with information that supports the design and production of these parts. The FEM interface of AVEVA Marine ${ }^{\circledR}$ to the Hull Structure Panel Model for automated FE-based structural optimisation is the main point of interest in this project. For more details, refer [12].

- modeFRONTIER®

The modeFRONTIER ${ }^{\circledR}$ software is a Multidisciplinary Design Optimisation (MDO) platform developed by ESTECO $\mathrm{SpA}$ [13]. Its workflow-based environment, and multi-objective optimisation algorithms are used for streamlining the engineering design process to cut time and cost while obtaining improved results. The software has three environments, each managing one step of the optimisation process. They are called Workflow Editor, Run Analysis and Design Space. In the present work modeFRONTIER ${ }^{\circledR}$ is employed as optimization tool and used a genetic algorithm available in its library. 


\subsection{In-house tools}

- Scantling-Spacing Updater

The Scantling-Spacing Updater is a new in-house tool (for 3D CAD model) developed to update the values of the structural design variables (i.e. plate thickness, stiffener scantling, stiffener spacing, etc.) in the AVEVA Marine ${ }^{\circledR} \mathrm{CAD}$ model. These structural design variables are subjected to technology and equality constraints from the yard/designer. The design variables proposed by modeFRONTIER $^{\circledR}$ are substituted with their corresponding structural design variables included in the scheme files and XML files of AVEVA Marine ${ }^{\circledast}$ to proceed with the generation of FE geometry model.

The history of stiffener size for deck 5 during an automated iterative process within the modeFRONTIER $^{\circledR}$ environment is shown in Fig. 2. The vertical axis is the stiffener type (Stiffener ID), selected within a list proposed by the yard, and the Stiffener ID varies from small to big stiffeners. The stiffener bulb profiles are automatically selected from the catalogue received by the yard. The variable is updated using the Scantling-Spacing Updater tool.

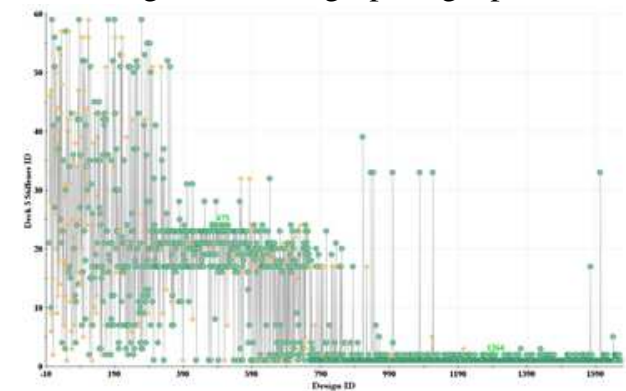

Fig.2. History of Deck 5 stiffener size during an automated iterative process

- FE Result Extractor

FE Result Extractor is a newly developed tool created with APDL scripts. The tool imports a solved FE model into ANSYS ${ }^{\circledR}$, extracts and exports the required FE results (e.g. longitudinal stress, shear stress, etc.) to strength assessment tool for carryout checks with respect to $\mathrm{BV}$ strength criteria $[14,15]$.

\section{- Strength Assessment Tool}

Strength assessment tool is developed on a Microsoft (MS) Excel basis, considering BV strength rules' requirements $[14,15]$, in order to check yielding and buckling of structural components such as plate panels and longitudinal stiffeners. The strength assessment tool uses FE analysis results as inputs and returns whether the structural elements (i.e. plates and longitudinal stiffeners) comply with the BV strength criteria or not.

- Loading Module

The structural strength of ships can be realistically performed only if the loads are assessed properly. The tools developed to implement the loads in FE analysis are based on $\mathrm{BV}$ rules for steel ships.

A newly developed tool, 'Rule-based Loading Module', is used to calculate the loads on the ship and to apply it on the finite element model. The module is developed with the help of Microsoft Excel and $\mathrm{JAVA}^{\mathrm{TM}}$ software. The hull girder loads are calculated by using a Microsoft Excel sheet created by implementing the equations defined in BV rules. The hull pressure at various locations is calculated by the executable created in JAVA ${ }^{\mathrm{TM}}$ software, which incorporates the equations to obtain the hull pressure in different conditions. The hull pressure obtained, using the developed in-house tool on the FE model, is shown in Fig. 3.

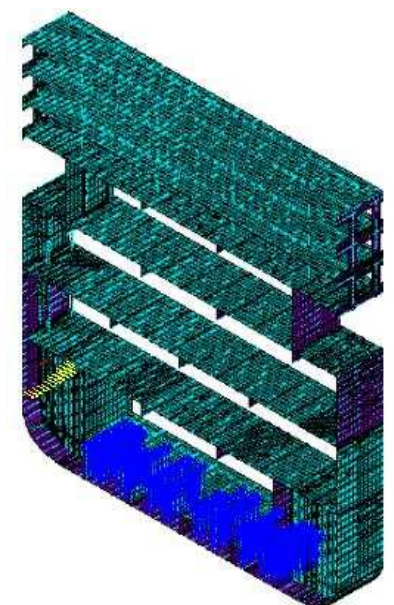

Fig.3. Hull pressure distribution on the FE model 


\section{DEMO CASE STUDY}

A typical RoPax ship was taken to demonstrate the FE-based structural assessment/optimisation development within the contract design phase. Based on the data available from the shipyard, a 3D CAD model was created in AVEVA Marine ${ }^{\circledR}$. The main dimensions of the RoPax vessel are given in Table 1 and the longitudinal view is shown in Fig. 4. Due to the confidentiality of the documents, midship and other drawings are not provided.

Table.1. Main particulars of the RoPax vessel

\begin{tabular}{|l|l|}
\hline Overall length & $217 \mathrm{~m}$ \\
\hline Breadth & $32.2 \mathrm{~m}$ \\
\hline Depth to main deck & $9.65 \mathrm{~m}$ \\
\hline Draft & $6.50 \mathrm{~m}$ \\
\hline Block coefficient & 0.629 \\
\hline Steel weight & 12273 tons \\
\hline
\end{tabular}

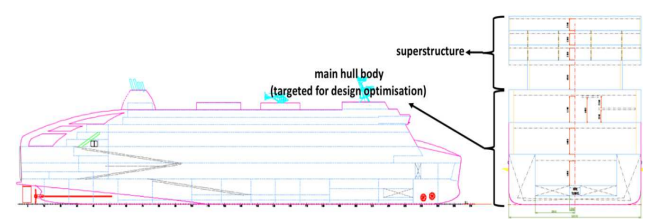

Fig.4. RoPax vessel longitudinal view

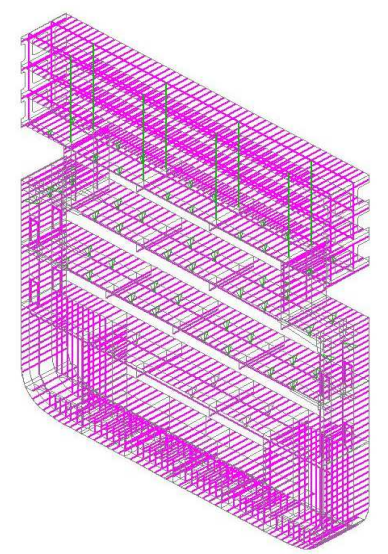

Fig.5. Idealised model between two mainframes
A segment from the parallel midbody of RoPax vessel was considered for optimisation (Fig. 5). The idealisation process of the 3D CAD model in AVEVA Marine ${ }^{\circledR}$ converts the longitudinal stiffeners into lines and the plates into areas. The girders and frames are also represented by areas for all the decks up to deck 9. The girders are merged as lines for deck 10, 11 and 12. The structural properties are internally defined in the model.

The finite element model of idealised section is provided with the help of the FE Modeller tool (integrated in AVEVA Marine $^{\circledR}$ ), which was later used by ANSYS ${ }^{\circledR}$ for FE-based structural assessment.

Hull girder loads (i.e. bending moments and shear forces) and pressure distribution over hull are calculated by the 'Loading Module'. The wheel loads are applied as distributed loads on the finite element model (Fig. 6).

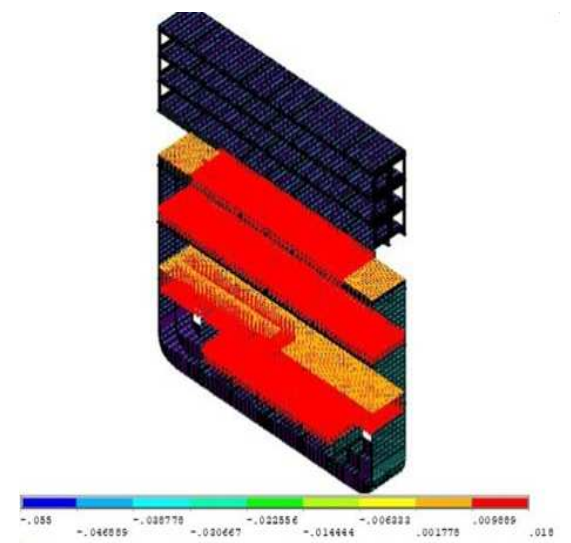

Fig.6. Wheel loads on FE model

\subsection{Selected Design Variables and their Lower / Upper Limits}

Table 2 lists the lower and upper bounds considered for the design variables in the optimisation process. The stiffener profiles are provided by the shipyard and the Table 2 lists the first and last HP profiles given in the database. The stiffener profiles are selected 
based on their database identification number during optimisation.

The design variables are composed of plate thickness, stiffener scantling and spacing, frame scantling and girder scantling. The range of design input variables are selected in accordance with the data received from shipyard.

Table.2. Lower and upper limits of design variables imposed by shipyard (unit is in $\mathbf{~ m m}$ )

\begin{tabular}{|l|c|c|}
\hline \multicolumn{1}{|c|}{$\begin{array}{c}\text { Design vari- } \\
\text { ables }\end{array}$} & $\begin{array}{c}\text { Lower } \\
\text { limit }\end{array}$ & $\begin{array}{c}\text { Upper } \\
\text { limit }\end{array}$ \\
\hline Plate thickness & 5 & 17 \\
\hline $\begin{array}{l}\text { Stiffener spac- } \\
\text { ing }\end{array}$ & 400 & 700 \\
\hline Stiffener profile & HP80x5 & HP430X21 \\
\hline $\begin{array}{l}\text { Frame web } \\
\text { height }\end{array}$ & 750 & 1150 \\
\hline $\begin{array}{l}\text { Frame web } \\
\text { thickness }\end{array}$ & 9 & 13 \\
\hline $\begin{array}{l}\text { Frame flange } \\
\text { width }\end{array}$ & 300 & 500 \\
\hline $\begin{array}{l}\text { Frame flange } \\
\text { thickness }\end{array}$ & 14 & 24 \\
\hline $\begin{array}{l}\text { Girder web } \\
\text { height }\end{array}$ & 7 & 1200 \\
\hline $\begin{array}{l}\text { Girder web } \\
\text { thickness }\end{array}$ & 200 & 500 \\
\hline $\begin{array}{l}\text { Girder flange } \\
\text { width }\end{array}$ & 7 & 20 \\
\hline $\begin{array}{l}\text { Girder flange } \\
\text { thickness }\end{array}$ & & 13 \\
\hline
\end{tabular}

\subsection{Selection of Constraints and their Limits}

The following constraints are considered during the FE-based structural assessment/optimisation process in addition to the technological constraints received from the yard (Table 2).

The yielding criteria was implemented in the optimisation workflow through constraint nodes. There are two materials in the model and the rule requirement imposes that the stresses in the materials should not go beyond the maximum allowable stress values for the corresponding materials. This maxi- mum allowable stress value for the materials is calculated using equation (1). The equation is defined in [14-15].

$$
\sigma_{V M}=\frac{235}{\gamma_{R} \gamma_{M} k}
$$

The resistance partial safety factor $\left(\gamma_{R}\right)$ and material partial safety factor $\left(\gamma_{M}\right)$ are respectively 1.2 and 1.02 for the 'general case' [15] of loading. The material factor $\mathrm{k}$ takes a value of 1 for material with yield stress $235 \mathrm{MPa}$ and 0.72 for material with yield stress $355 \mathrm{MPa}$. The finite element results, extracted for a design (ID 185) during optimisation, are shown in Fig. 7.

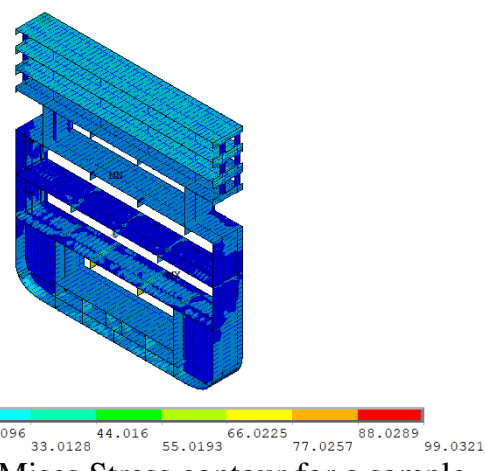

Fig.7. von Mises Stress contour for a sample design

The evolution of the maximum von Mises stress for deck 3 plate during optimisation, which has a yield stress of $355 \mathrm{MPa}$, is shown in Fig. 8.

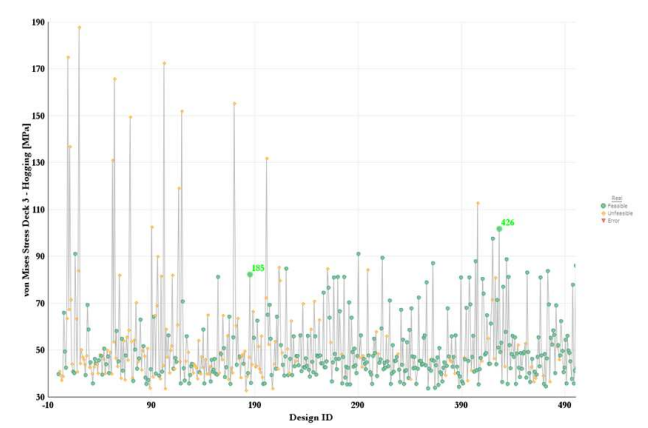

Fig.8. History of von Mises Stress for deck 3 plate within an automated iterative process 


\subsection{Results and Discussion}

The structural assessment-optimisation of the RoPax vessel was carried out in the modeFRONTIER $^{\circledR}$ environment. NSGA-II (NonDominated Sorting Genetic Algorithm) was selected as the optimisation algorithm from modeFRONTIER ${ }^{\circledR}$ algorithms library.

The FE based structural optimisation workflow optimises the plating, stiffener spacing, stiffeners, frames and girders scantlings. Fig. 9 shows the history of the ship steel weight from the automated iterative process. The figure clearly shows that the optimisation process goes towards a reduced weight configuration for the ship.

A detailed comparison between the scantling of the reference design (ID 0), the averaged feasible solution (ID 1586) and the proposed feasible alternative design (ID 1638) for various structural members are carried out. The comparison for deck 1 is given in Table 3 as an example.

Table.3. Comparison of initial and improved design variables for deck 1

\begin{tabular}{|c|c|c|c|}
\hline $\begin{array}{c}\text { Design } \\
\text { variables }\end{array}$ & $\begin{array}{c}\text { ID } 0 \\
\text { (Refer- } \\
\text { ence } \\
\text { design) }\end{array}$ & $\begin{array}{l}\text { ID } 1586 \\
\text { (Average } \\
\text { Improved } \\
\text { Solution) }\end{array}$ & $\begin{array}{c}\text { ID } 1638 \\
\text { (Solution } \\
\text { for Least } \\
\text { Steel } \\
\text { Weight) }\end{array}$ \\
\hline $\begin{array}{c}\text { Plate } \\
\text { thickness }\end{array}$ & 12.0 & 7.5 & 5.0 \\
\hline $\begin{array}{c}\text { Stiffener } \\
\text { spacing }\end{array}$ & 600 & 700 & 500 \\
\hline $\begin{array}{l}\text { Stiffener } \\
\text { profile }\end{array}$ & $\begin{array}{c}\text { HP } \\
200 \times 10\end{array}$ & $\begin{array}{c}\mathrm{HP} \\
370 \times 14\end{array}$ & $\begin{array}{c}\text { HP } \\
300 \times 12\end{array}$ \\
\hline $\begin{array}{c}\text { Frame } \\
\text { web } \\
\text { height }\end{array}$ & 450 & 420 & 500 \\
\hline $\begin{array}{c}\text { Frame } \\
\text { web } \\
\text { thickness }\end{array}$ & 8.0 & 12.0 & 12.0 \\
\hline $\begin{array}{l}\text { Frame } \\
\text { flange } \\
\text { width }\end{array}$ & 150 & 180 & 180 \\
\hline $\begin{array}{c}\text { Frame } \\
\text { flange } \\
\text { thickness }\end{array}$ & 10.0 & 9.0 & 9.5 \\
\hline $\begin{array}{c}\text { Steel } \\
\text { Weight }[t]\end{array}$ & 12296.0 & 11713.77 & 10812.41 \\
\hline
\end{tabular}

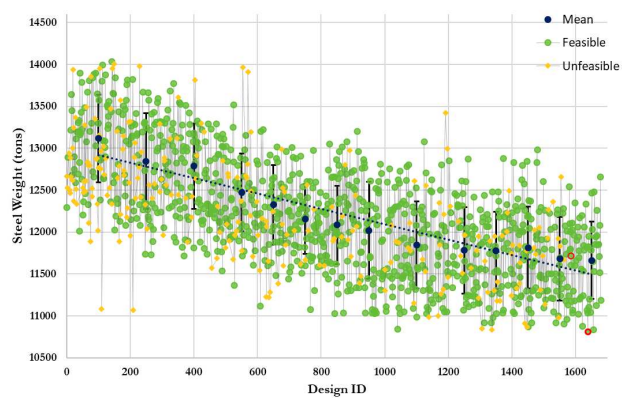

Fig.9. History of steel weight evolution during optimisation

The optimisation process was also carried out for RoPax vessels with different dimensions to show the applicability of the developed tools. The results suggest that the tools can be applied to RoPax vessel optimisation in the contract stage.

The improved steel weight of the ship against ship's beam for various frame spacings is plotted in Fig. 10. The results plotted in Fig. 10 are obtained by modifying the beam $(29.2 \mathrm{~m}, 32.2 \mathrm{~m}$ and $35.2 \mathrm{~m})$ and frame spacing (2100 mm, $2400 \mathrm{~mm}$ and $2700 \mathrm{~mm}$ ) while keeping the length $(210 \mathrm{~m})$ of the ship constant.

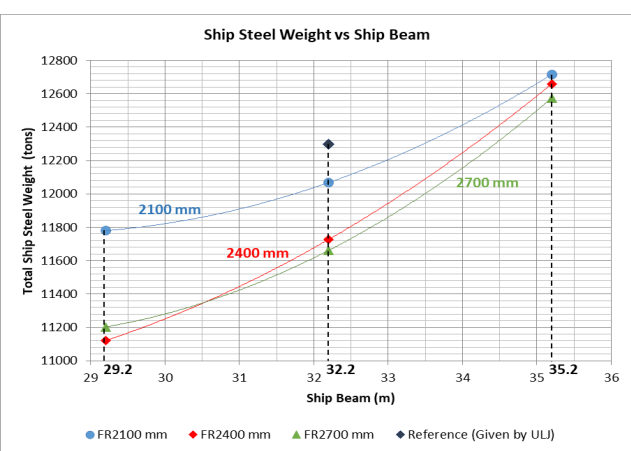

Fig.10. Ship steel weight vs ship beam for various frame spacing

It is evident from the graph that the optimisation process reduced the steel weight of the Reference design by approximately $5 \%$. The steel weight of ship models with different beams and constant frame spacing of $2100 \mathrm{~mm}$ are more than that with larger frame spacing as expected. 
The gap in ship steel weight between different frame spacing is higher for smaller ship beams and it gradually decreases with the increase in ship beams. The decrease in the gap can be explained with the increase in the bending moment due to higher ship beams. As the hull girder bending moment increases, the stress in the plates and stiffeners increases. In order to reduce the stress on the structural components, the optimiser proposes thicker plates and stiffeners with larger cross section, which resulted in higher weights. The trend lines suggesting that, if the ship beam increases, a model with 2100 $\mathrm{mm}$ frame spacing may result in less weight than $2400 \mathrm{~mm}$ and $2700 \mathrm{~mm}$ frame spacing.

\section{CONCLUDING REMARKS}

The presented outcomes can give an insight into a new way for holistic ship design by integrating existing tools such as AVEVA Marine $^{\circledR}$, ANSYS $^{\circledR}$ and modeFRONTIER ${ }^{\circledR}$ in a single platform, which will ensure reliable assessment of ship design alternatives within a feasible time frame. The successful implementation of the workflow and the in-house tools show that the present methodology can be taken to an industrial level by providing a user friendly graphical interface to the development.

\section{Acknowledgements}

The authors wish to acknowledge the support provided by the H2020 project 'HOLISHIP- Holistic Optimization of Ship Design and Operation for Life Cycle' under contract no. 689074.

\section{\begin{tabular}{l|l} 
Eorizon 2020 \\
foropean Union funding \\
forearch \& Innovation
\end{tabular}}

The authors appreciate the support given to the current development by AVEVA Marine $^{\circledR}$, CNR-INSEAN and Bureau Veritas.

\section{REFERENCES}

[1]. IMPROVE, "Design of improved and competitive products using an integrated decision support system for ship production and operation", EU, 2006.
[2]. Klanac, A., Varsta, P., "Design of marine structures with improved safety for environment", Reliability Engineering and System Safety, 96, pp 75-90, 2011.

[3]. Rigo, P., Ehlers, S., Zanic, V., Andric, J., "Design of innovative ship concepts using an integrated decision support system for ship production and operation", Brodogradnja, 61(4), pp 367-381, 2010.

[4]. BESST, "Breakthrough in European Ship and Shipbuilding Technologies", EU, 2007.

[5]. Bayatfar, A., Amrane, A., Rigo, P., "Towards a ship structural optimization methodology at early design stage", Int. J. of Engineering Research and Development, 9(6), pp 76-90, 2013.

[6]. Papanikolaou, A., "Holistic ship design optimization", Journal Computer-Aided Design, Elsevier, 42(11), pp 1028-1044, 2010.

[7]. HOLISHIP, "Holistic optimization of ship design and operation for life cycle", EU, 2016.

[8]. Papanikolaou, A. (Ed.), "A holistic approach to ship design-Vol. 1: Optimization of ship design and operation for life cycle", Springer, 2019.

[9]. Harries, S., Cau, C., Marzi, J., Kraus, A., Papanikolaou, A., Zaraphonitis, G., "Software platform for the holistic design and optimization of ships", STG Jahrbuch, 2017.

[10]. Marzi, J., Papanikolaou, A., Brunswig, J., Corrignan, P., Zaraphonitis, G., Harries, S., "HOLISTIC ship design optimization", 13th Int. Marine Design Conference, 2018.

[11]. Rigo, P., Bayatfar, A., Buldgen, L., Pire, T., Echeverry Jaramillo, S., Caprace, J.D., "Optimization of ship and offshore structures and effective waterway infrastructures to support the global economic growth of a country/region", Ship \& Science Technology, 11:9-27, 2017.

[12]. Hull Detailed Design- Planar Hull ModellingScheme file, Rev 8.0, AVEVA Marine, 2017.

[13]. https://www.esteco.com/modefrontier

[14]. Bureau Veritas - Guidance Note for Structural Assessment of Passenger Ships and RoRo Passenger Ships (NI640), 2018

[15]. Bureau Veritas - Part B: Hull and Stability, Rules for the classification of steel ships (NR467), 2018

Paper received on November $10^{\text {th }}, 2019$ 